\title{
MEMPERKIRAKAN PERBANDINGAN KADAR AIR SEMEN PADA BETON KERAS
}

\author{
Widodo Kushartomo ${ }^{1}$, Arianti Sutandi², Dewi Linggasari ${ }^{3}$ \\ ${ }^{1}$ Program Studi Sarjana Teknik Sipil, Universitas Tarumanagara Jakarta \\ Email:widodo@untar.ac.id \\ ${ }^{2}$ Program Studi Sarjana Teknik Sipil, Universitas Tarumanagara Jakarta \\ Email:ariantis@ft.untar.ac.id \\ ${ }^{3}$ Program Studi Sarjana Teknik Sipil, Universitas Tarumanagara Jakarta \\ Email:dewil@ft.untar.ac.id
}

Masuk: 26-02-2020, revisi: 26-05-2020, diterima untuk diterbitkan: 27-05-2020

\begin{abstract}
ABSTRAK
Perbandingan kadar air semen (w/c-ratio) merupakan salah satu faktor penting untuk menentukan kekuatan beton, sehingga penting sekali mengetahui perbandingan jumlah air yang digunakan dalam suatu adukan beton. Banyak permasalahan yang muncul terkait mutu beton pada bangunan yang sudah jadi memerlukan penyelidikan yang mendalam terhadap komposisi material beton tersebut guna memperkirakan mutu beton termasuk didalamnya perbandingan jumlah air terhadap semen. Memperkirakan perbandingan jumlah air terhadap jumlah semen pada beton keras bukan merupakan suatu perkara yang mudah, ada banyak faktor yang mempengaruhinya. Diperlukan sejumlah pengujian khusus pada beton keras untuk mendapatkan akurasi nilai perbandingan kadar air semen $(w / c$ ratio). Sejumlah benda uji disiapkan untuk pengujian dengan kadar air dan jumlah semen yang telah diketahui. Setelah melalui proses perawatan selama 28 hari, pada umur 60 hari seluruh benda uji diperiksa baik secara kimiawi maupun secara volumetrik untuk menghitung ulang jumlah air dan semen yang telah digunakan. Hasil perhitungan menunjukkan teknik yang digunakan memiliki kesesuaian sebesar 99\% terhadap perencanaan.
\end{abstract}

Kata Kunci: air; semen; kimiawi; volumetrik; komposisi.

\begin{abstract}
Comparison of cement water content ( $w / c$-ratio) is one important factor to determine the strength of concrete, so it is important to know the ratio of the amount of water used in a concrete mix. Many problems that arise related to the quality of concrete in ready-made buildings require an in-depth investigation of the composition of concrete materials in order to estimate the quality of concrete including the ratio of the amount of water to cement. Estimating the ratio of the amount of water to the amount of cement in hard concrete is not an easy matter, there are many factors that influence it. A number of special tests are needed on hard concrete to get the accuracy of the ratio of cement water content ( $w /$ c-ratio). A number of test specimens were prepared for testing with known water content and amount of cement. After going through the treatment process for 28 days, at the age of 60 days all test specimens are examined both chemically and volumetricly to recalculate the amount of water and cement that has been used. The calculation results show the technique used has a suitability of $99 \%$ to the planning.
\end{abstract}

Keywords: water; cement; chemical; volumetricly; composition.

\section{PENDAHULUAN}

\section{Latar Belakang}

Perubahan perbandingan kadar air semen (w/c-ratio) pada beton mempunyai pengaruh sangat besar terhadap kuat tekan dan keawetan beton (Mindes dan Young, 1981). Bila membandingkan dua rencana campuran beton yang sama, beton dengan perbandingan kadar air semen (w/c-ratio) lebih kecil akan menghasilkan kuat tekan lebih tinggi dan tingkat permeabilitas lebih rendah, bila dibandingkan dengan campuran dengan perbandingan kadar air semen (w/c-ratio) lebih tinggi. 
Pada proses hidrasi semen yaitu reaksi antara semen dengan air, akan membentuk kalsium silikat hidrat/ gel (C-S-H), kalsium hidroksida $(\mathrm{CaOH})$ dan etringite (Neville, 2011). Pembentukan C-S$\mathrm{H}, \mathrm{CaOH}$ dan etringite terus berkembang dan saling terhubung mengurangi jumlah por-pori pasta semen. Pengetahuan tentang pori-pori sangat bermfaat ketika pori-pori memiliki pengaruh pada kekuatan beton. Jumlah pori-pori yang terbentuk pada beton, menggambarkan rekam jejak air, sehingga jumlah pori-pori juga dapat menggambarkan jumlah air yang digunakan sebagai campuran beton (Tauqir, 2018).

Beton pada umumnya dipesan berdasarkan nilai kuat tekan dan tinggi slump. Nilai kuat tekan diperlukan untuk kriteria perencanaan struktur, sedangkan nilai slump diperlukan untuk mengukur tingkat kemudahan dalam pengecoran. Semakin tinggi nilai slump maka semakin mudah tingkat pengecorannya, tingginya nilai slump menggambarkan jumlah air yang digunakan. Terdapat pemahaman yang terbalik antara kuat tekan dengan perbandingan kadar air semen (w/c-ratio). Semakin tinggi nilai perbandingan kadar air semen (w/c-ratio), maka nilai kuat tekan beton semakin rendah (Neville, 2003).

Dalam pekerjaan pembetonan dilapangan sering dijumpai permasalahan mutu beton yang direncanakan tidak sesuai dengan kenyataan di lapangan. Ketidak sesuaian antar mutu beton yang direncanakan dengan mutu beton dilapangan merupakan masalah yang sangat serius dalam konstruksi bangunann. Keseriusan permasalahan ini karena menyangkut keamanan dan keselamatan pengguna bangungan. Seorang perencana bangunan memerlukan ketepatan dalam disain struktur bangunan, sehingga apabila terjadi ketidak sesuaian dengan spesifikasi yang direncanakan akan berdampak pada keamanan struktur bangunan tersebut. Ketidak sesuaian anatara mutu beton rencana dan kondisi di lapangan menimbulkan sengketa antara pihak-pihak yang berkepentingan. Salah satu acuan yang digunakan untuk mengatasi sengketa mutu beton tersebut adalah menghitung ulang komposisi material penyusun beton keras berupa perbandingan jumlah air, semen, pasir dan kerikil. Perbandingan kadar air semen (w/c-ratio) adalah hal utama yang ingin diketahui oleh para pihak yang bersengketa, mengingat perbandingan kadar air semen (w/c-ratio) terkait erat dengan kuat tekan beton (Neville, 2011).

Penentuan komposisi material pada beton yang sudah mengeras, bukan merupakan suatu perkara yang mudah terutama kadar air dan kadar semen. Banyak sekali faktor yang mempengaruhi nilai kadar air dan kadar semen diantaranya, ketelitian, alat, temperatur, kelembapan, material pozolanik, volume pori-pori dan sebagainya. Kesemuanya dapat menghambat penentuan nilai kadar air dan kadar semen.

Pada makalah ini disajikan perbandingan kadar air semen (w/c-ratio) pada beton yang sudah mengeras, dihitung dengan metode volumetric dengan berbagai variasi jumlah air semen pada beton. Metode ini dipilih mengingat kemudahan dalam pelaksanaan di lapangan dan ketersedian peralatan.

\section{Rumusan Masalah}

Berdasarkan latar belakang seperti yang telah diuraikan tersebut diatas, yang menjadi pokok permasalahan dalam penelitian ini, apakah jumlah silika dan kalsium yang terdeteksi pada kalsium silikat hidrat dapat menggambarkan kadar semen pada beton? Apakah volume pori-pori pada beton keras dapat menggambarkan jumlah air yang digunakan pada campuran beton. 


\section{METODE PENELITIAN}

Untuk dapat mencapai tujuan, dan menjawab semua pertanyaan pada penelitian ini, metode penelitian yang digunakan adalah penelitian eksperimental, dengan membuat benda uji berupa silinder beton berukuran diameter $10 \mathrm{~cm}$ dan tinggi $20 \mathrm{~cm}$ dengan komposisi seperti yang disajikan pada Tabel 1, yang kemudian dilakukan perawatan dengan cara perendaman dalam air selama 28 hari. Pengujian dilakukan pada seluruh benda uji pada umur 60 hari. Pengujian yang dilakukan berupa pengujian komposisi kimia dari setiap rencana campuran untuk mengetahui kandungan $\mathrm{CaO}$ dan $\mathrm{SiO}_{2}$, kemudian dilanjutkan dengan pengujian volumetrik untuk menghitung kadar agregat dalam campuran.

Tabel 1. Perancangan campuran contoh uji

\begin{tabular}{lccc}
\hline Material & $A$ & $B$ & $C$ \\
\hline Semen & 1 & 1 & 1 \\
\hline Air & 0.50 & 0.50 & 0.50 \\
\hline Pasir & 0 & 2,0 & 2,0 \\
\hline Kerikil & 0 & 0 & 3,0 \\
\hline
\end{tabular}

\section{HASIL DAN PEMBAHASAN}

Data yang dihasilkan dalam penelitian disajikan pada table-tabel berikut;

Tabel 2. Komposisi kimia benda uji beton kode A

\begin{tabular}{lccc}
\hline \multicolumn{1}{c}{ Parameter } & Unit & Results & Method \\
\hline Iron Trioxide $\left(\mathrm{Fe}_{2} \mathrm{O}_{3}\right)$ & $\%$ & 4.59 & $\mathrm{PO} / \mathrm{MOM} / 24$ \\
\hline Aluminium Trioxide $\left(\mathrm{Al}_{2} \mathrm{O}_{3}\right)$ & $\%$ & 10.49 & $\mathrm{PO} / \mathrm{MOM} / 24$ \\
\hline Calcium Oxide $(\mathrm{CaO})$ & $\%$ & 9.96 & $\mathrm{PO} / \mathrm{MOM} / 24$ \\
\hline Magnesium Oxide $(\mathrm{MgO})$ & $\%$ & 1.06 & $\mathrm{PO} / \mathrm{MOM} / 24$ \\
\hline Manganese Dioxide $\left(\mathrm{MnO}_{2}\right)$ & $\%$ & 0.07 & $\mathrm{PO} / \mathrm{MOM} / 24$ \\
\hline Chromium Trioxide $\left(\mathrm{Cr}_{2} \mathrm{O}_{3}\right)$ & $\%$ & 0.01 & $\mathrm{PO} / \mathrm{MOM} / 24$ \\
\hline Sodium Oxide $\left(\mathrm{Na}_{2} \mathrm{O}\right)$ & $\%$ & 1.41 & $\mathrm{PO} / \mathrm{MOM} / 24$ \\
\hline Potassium Oxide $\left(\mathrm{K}_{2} \mathrm{O}\right)$ & $\%$ & 1.02 & $\mathrm{PO} / \mathrm{MOM} / 24$ \\
\hline Silicon Dioxide $\left(\mathrm{SiO}_{2}\right)$ & $\%$ & 65.18 & $\mathrm{PO} / \mathrm{MOM} / 24$ \\
\hline Titanium Dioxide $\left(\mathrm{TiO}_{2}\right)$ & $\%$ & 0.40 & $\mathrm{PO} / \mathrm{MOM} / 24$ \\
\hline Loss On Ignition $(\mathrm{LOI})$ & $\%$ & 5.17 & $\mathrm{PO} / \mathrm{MOM} / 24$ \\
\hline Moisture Content $(\mathrm{MC})$ & $\%, \mathrm{AR}$ & 2.93 & $\mathrm{PO} / \mathrm{MOM} / 24$ \\
\hline
\end{tabular}

Tabel 3. Komposisi kimia benda uji beton kode B

\begin{tabular}{lccc}
\hline \multicolumn{1}{c}{ Parameter } & Unit & Results & Method \\
\hline Iron Trioxide $\left(\mathrm{Fe}_{2} \mathrm{O}_{3}\right)$ & $\%$ & 4.01 & ICP \\
\hline Aluminium Trioxide $\left(\mathrm{Al}_{2} \mathrm{O}_{3}\right)$ & $\%$ & 9.66 & ICP \\
\hline Calcium Oxide $(\mathrm{CaO})$ & $\%$ & 9.20 & ICP \\
\hline Magnesium Oxide $(\mathrm{MgO})$ & $\%$ & 1.43 & ICP \\
\hline Manganese Dioxide $\left(\mathrm{MnO}_{2}\right)$ & $\%$ & 0.08 & ICP \\
\hline Chromium Trioxide $\left(\mathrm{Cr}_{2} \mathrm{O}_{3}\right)$ & $\%$ & Less than 0.01 & ICP \\
\hline Sodium Oxide $\left(\mathrm{Na}_{2} \mathrm{O}\right)$ & $\%$ & 1.86 & ICP \\
\hline Potassium Oxide $\left(\mathrm{K}_{2} \mathrm{O}\right)$ & $\%$ & 1.71 & ICP \\
\hline Silicon Dioxide $\left(\mathrm{SiO}_{2}\right)$ & $\%$ & 64.41 & ICP \\
\hline Titanium Dioxide $\left(\mathrm{TiO}_{2}\right)$ & $\%$ & 0.98 & ICP \\
\hline Loss On Ignition $(\mathrm{LOI})$ & $\%$ & 6.28 & Gravimetric \\
\hline Moisture Content $(\mathrm{MC})$ & $\%$, AR & 3.70 & Gravimetric \\
\hline
\end{tabular}


Tabel 4. Komposisi kimia benda uji beton kode $\mathrm{C}$

\begin{tabular}{lccc}
\hline \multicolumn{1}{c}{ Parameter } & Unit & Results & Method \\
\hline Iron Trioxide $\left(\mathrm{Fe}_{2} \mathrm{O}_{3}\right)$ & $\%$ & 4.55 & ICP \\
\hline Aluminium Trioxide $\left(\mathrm{Al}_{2} \mathrm{O}_{3}\right)$ & $\%$ & 10.25 & ICP \\
\hline Calcium Oxide $(\mathrm{CaO})$ & $\%$ & 9.57 & ICP \\
\hline Magnesium Oxide $(\mathrm{MgO})$ & $\%$ & 1.85 & ICP \\
\hline Manganese Dioxide $\left(\mathrm{MnO}_{2}\right)$ & $\%$ & 0.09 & ICP \\
\hline Chromium Trioxide $\left(\mathrm{Cr}_{2} \mathrm{O}_{3}\right)$ & $\%$ & 0.01 & ICP \\
\hline Sodium Oxide $\left(\mathrm{Na}_{2} \mathrm{O}\right)$ & $\%$ & 1.89 & ICP \\
\hline Potassium Oxide $\left(\mathrm{K}_{2} \mathrm{O}\right)$ & $\%$ & 1.62 & ICP \\
\hline Silicon Dioxide $\left(\mathrm{SiO}_{2}\right)$ & $\%$ & 60.15 & ICP \\
\hline Titanium Dioxide $\left(\mathrm{TiO}_{2}\right)$ & $\%$ & 1.13 & ICP \\
\hline Loss On Ignition $(\mathrm{LOI})$ & $\%$ & 6.51 & Gravimetric \\
\hline Moisture Content $(\mathrm{MC})$ & $\%$, AR & 4.17 & Gravimetric \\
\hline
\end{tabular}

Prosentase semen dalam beton $\left(\mathrm{C}_{\mathrm{c}}\right)$, dihutung berdasarkan jumlah $\mathrm{CaO}$ yang terukur berdasarkan uji analisa kimia. Berdasarkana data yang diperoleh seperti disajikan dalam Tabel 2 sampai dengan Tabel 4, jumlah prosentase semen dalam beton dihitung sebagai berikut:

$$
C_{c}=\frac{A}{B} \times 100
$$

dimana:

$\mathrm{C}_{\mathrm{c}}=$ prosentase semen dalam beton; $\mathrm{A}=\% \mathrm{CaO}$ dalam beton; $\mathrm{B}=\% \mathrm{CaO}$ dalam semen

Apabila tidak tersedia data,nilai \% $\mathrm{CaO}$ dalam semen menurut ASTM ditetapkan sebesar 63,5\%. Namun apabila di kemudian hari terdapat sumber resmi dari produsen semen berkaitan dengan kadar $\mathrm{CaO}$ dalam semen, maka nilai prosentase semen dalam beton berdasarkan perhitungan ini dapat dikoreksi lagi.

Tabel 5. Persentase jumlah semen dalam beton

\begin{tabular}{llcccc}
\hline \multirow{2}{*}{ No } & \multirow{2}{*}{ Parameter } & Unit & \multicolumn{3}{c}{ Kode } \\
\cline { 4 - 6 } & & & $\mathrm{A}$ & $\mathrm{B}$ & $\mathrm{C}$ \\
\hline 1 & $\mathrm{CaO}$ (dalam beton) & $\%$ & 11,3 & 10,0 & 9,1 \\
\hline 2 & $\mathrm{CaO}$ (dalam semen) & $\%$ & 63,5 & 63,5 & 63,5 \\
\hline 3 & $\mathrm{C}_{\mathrm{c}}$ (semen dalam beton) & $\%$ & 17,7 & 15,7 & 14,3 \\
\hline
\end{tabular}

\section{a. Perhitungan berat jenis beton}

Berat jenis beton kering permukaan $\left(\mathrm{D}_{\text {ssd }}\right)$, dihitung berdasarkan data yang disajikan dalam Tabel 6 , dengan persamaan:

$$
D_{s s d}=\frac{W_{1} \times \rho}{W_{1}-W_{2}}
$$

dimana:

$\rho \quad=$ kerapatan (density) air $=997 \mathrm{~kg} / \mathrm{m}^{3}$

Berat jenis beton kering permukaan $\left(\mathrm{D}_{\mathrm{ssd}}\right)$, dihitung berdasarkan data yang disajikan dalam Tabel 6, dengan persamaan:

$$
D_{\text {dry }}=\frac{D_{\text {ssd }} \times W_{3}}{W_{1}}
$$


Tabel 6. Massa sampel beton

\begin{tabular}{|c|c|c|c|c|c|c|c|c|c|c|c|}
\hline \multirow{2}{*}{ No } & \multirow{2}{*}{ Parameter } & \multirow{2}{*}{ Unit } & \multicolumn{3}{|c|}{ Kode A } & \multicolumn{3}{|c|}{ Kode B } & \multicolumn{3}{|c|}{ Kode C } \\
\hline & & & 1 & 2 & 3 & 1 & 2 & 3 & 1 & 2 & 3 \\
\hline 1 & Massa beton awal, $\left(\mathrm{W}_{0}\right)$ & $\mathrm{g}$ & 505,5 & 475,5 & 460,0 & 34,0 & 479,0 & 443,0 & 550,5 & 521,5 & 510,5 \\
\hline 2 & $\begin{array}{l}\text { Massa beton SSD di } \\
\text { udara, }\left(\mathrm{W}_{1}\right)\end{array}$ & $\mathrm{g}$ & 518,0 & 491,5 & 473,8 & 545,0 & 488,0 & 451,0 & 563,0 & 532,5 & 517,0 \\
\hline 3 & $\begin{array}{l}\text { Massa beton SSD di air, } \\
\left(\mathrm{W}_{2}\right)\end{array}$ & $\mathrm{g}$ & 298,0 & 270,5 & 259,0 & 301,5 & 266,0 & 245,5 & 311,5 & 303,5 & 286,5 \\
\hline 4 & $\begin{array}{l}\text { Massa beton kering } \\
\text { oven, }\left(\mathrm{W}_{3}\right)\end{array}$ & $\mathrm{g}$ & 492,5 & 464,5 & 448,3 & 518,5 & 461,0 & 425,5 & 536,0 & 505,5 & 494,0 \\
\hline
\end{tabular}

Tabel 7. Berat jenis rata-rata sampel beton

\begin{tabular}{lllccc}
\hline \multirow{2}{*}{ No } & \multirow{2}{*}{ Parameter } & \multirow{2}{*}{ Unit } & \multicolumn{3}{c}{ Kode } \\
\cline { 4 - 6 } & & & $\mathrm{A}$ & $\mathrm{B}$ & $\mathrm{C}$ \\
\hline 1 & $\mathrm{D}_{\text {SSD }}$ & $\mathrm{kg} / \mathrm{m}^{3}$ & $2.209,24$ & $2.345,20$ & $2.216,08$ \\
\hline 2 & D $_{\text {DRY }}$ & $\mathrm{kg} / \mathrm{m}^{3}$ & $2.093,10$ & $2.044,05$ & $2.110,91$ \\
\hline
\end{tabular}

\section{b. Jumlah semen dalam beton}

Jumlah semen dalam beton dihitung dengan persamaan:

$$
\mathrm{C}, \mathrm{kg} / \mathrm{m}^{3}=\frac{\left(\mathrm{C}_{\mathrm{c}} \times \mathrm{D}_{\mathrm{dry}}\right)}{100}
$$

dimana: $\mathrm{C}=$ jumlah semen

Tabel 8. Massa semen dalam beton

\begin{tabular}{lccccc}
\hline \multirow{2}{*}{ No } & \multirow{2}{*}{ Parameter } & \multirow{2}{*}{ Unit } & \multicolumn{3}{c}{ Kode } \\
\cline { 4 - 6 } & & & $\mathrm{A}$ & $\mathrm{B}$ & $\mathrm{C}$ \\
\hline 1 & Cement & $\mathrm{kg} / \mathrm{m} 3$ & 370,47 & 320,91 & 301,86 \\
\hline
\end{tabular}

\section{c. Air}

Perhitungan jumlah air dalam beton meliputi dua bagian yaitu jumlah air terikat (combained water) $\mathrm{W}_{\mathrm{c}}$, dan jumlah air bebas (free water) $\mathrm{W}_{\mathrm{f}}$. Jumlah air total (W) yang dimaksud adalah air yang terikat ditambah dengan air bebas

Jumlah air bebas, $\mathrm{L}_{\mathrm{f}}$ dihitung berdasarkan data yang disajikan dalam Tabel 6, dengan persamaan:

$$
L_{f}=\frac{\left(W_{1}-W_{3}\right)}{\left(W_{1}-W_{2}\right)} \times \rho
$$

Sedangkan jumlah air terikat dihitung berdasarkan persamaan:

$$
\mathrm{L}_{\mathrm{c}}=\frac{\left(\mathrm{w}_{5}-\mathrm{w}_{4}\right)}{\mathrm{w}_{5}} \times 100 \%
$$

dan Jumlah air total merupakan gabungan antara jumlah air bebas $\mathrm{L}_{\mathrm{f}}$ dan jumlah air terikat $\mathrm{L}_{\mathrm{c}}$ yaitu: 


$$
\mathrm{W}=\mathrm{L}_{\mathrm{f}}+\mathrm{L}_{\mathrm{c}}
$$

dimana:

$\mathrm{L}_{\mathrm{c}}=$ jumlah air terikat, $\%$

$\mathrm{L}_{\mathrm{f}}=$ jumlah air bebas, $\mathrm{kg} / \mathrm{m}^{3}$

$\mathrm{W}=$ jumlah air total

Tabel 9. Jumlah air total sampel beton

\begin{tabular}{|c|c|c|c|c|c|c|c|c|c|c|c|}
\hline \multirow{2}{*}{ No } & \multirow{2}{*}{ Parameter } & \multirow{2}{*}{ Unit } & \multicolumn{3}{|c|}{ Kode A } & \multicolumn{3}{|c|}{ Kode B } & \multicolumn{3}{|c|}{ Kode C } \\
\hline & & & 1 & 2 & 3 & 1 & 2 & 3 & 1 & 2 & 3 \\
\hline 1 & $\begin{array}{l}\text { Massa beton } \\
\text { kering oven, }\left(\mathrm{W}_{3}\right)\end{array}$ & g & 10,00 & 10,00 & 10,00 & 10,00 & 10,00 & 10,00 & 10,00 & 10,00 & 10,00 \\
\hline 2 & $\begin{array}{l}\text { Massa beton kering } \\
520^{\circ} \mathrm{C},\left(\mathrm{W}_{4}\right)\end{array}$ & $\mathrm{g}$ & 9,59 & 9,63 & 9,61 & 9,77 & 9,68 & 9,7 & 9,89 & 9,95 & 9,81 \\
\hline 3 & $\mathrm{~L}_{\mathrm{c}}$ & $\%$ & 4,10 & 3,70 & 3,90 & 2,30 & 3,20 & 3,00 & 1,10 & 0,50 & 1,90 \\
\hline 4 & $\mathrm{D}_{\mathrm{DRY}}$ & $\mathrm{kg} / \mathrm{m}^{3}$ & & 2093,07 & & & 2044,05 & & & 2110,91 & \\
\hline \multirow{2}{*}{5} & \multirow{2}{*}{$\mathrm{L}_{\mathrm{c}}$} & \multirow{2}{*}{$\mathrm{kg} / \mathrm{m}^{3}$} & 85,82 & 77,44 & 81,63 & 47,01 & 65,41 & 61,32 & 23,22 & 10,55 & 40,11 \\
\hline & & & & 81,63 & & & 57,91 & & & 24,63 & \\
\hline 6 & $\mathrm{LF}_{\mathrm{F}}$ & $\mathrm{kg} / \mathrm{m}^{3}$ & & 118,61 & & & 129,49 & & & 129,49 & \\
\hline 9 & $\mathrm{~W}$ & $\mathrm{~kg} / \mathrm{m}^{3}$ & & 200,24 & & & 187,41 & & & 154,12 & \\
\hline
\end{tabular}

\section{d. Agregat Kasar dan Agregat Halus}

Agregat kasar atau kerikil dalam campuran beton pada umumnya adalah batuan andesit, Batuan andesit tersusun dari beberapa mineral dengan komposisi utama adalah plagioklas dengan kadar mencapai 70\%. Dalam struktur batuan andesit, diketemukan unsur silika ataupun alumina, (Mottana, dkk. 1978)

Agregat halus atau pasir yang digunakan dalam pembuatan beton, pada umumnya mengandung silika, bahkan terdapat beberapa agregat halus dengan kadar silika sangat tinggi, sebagai contohnya pasir bangka dan pasir silika. Tetapi tidak semua agregat halus mengandung banyak silika tergantung dari sumber atau daerah asal agregat halus tersebut.

Berdasarkan data yang diberikan pada Tabel 4.4 jumlah agregat yang digunakan dalam campuran beton adalah sebesar:

$$
\mathrm{C}_{\mathrm{a}}+\mathrm{F}_{\mathrm{a}}=\mathrm{DSSD}_{\text {SS }}-\mathrm{C}-\mathrm{W}
$$

dimana: $\mathrm{C}_{\mathrm{a}}=$ massa agregat $\mathrm{kasar}$ (kerikil), $\mathrm{kg} ; \mathrm{F}_{\mathrm{a}}=$ massa agregat halus (pasir), $\mathrm{kg}$

Tabel 10. Jumlah agregat dalam beton

\begin{tabular}{llrrrr}
\hline \multirow{2}{*}{ No } & \multirow{2}{*}{ Parameter } & \multirow{2}{*}{ Unit } & \multicolumn{3}{c}{ Kode } \\
\cline { 4 - 6 } & & & \multicolumn{1}{c}{$\mathrm{A}$} & \multicolumn{1}{c}{$\mathrm{B}$} & \multicolumn{1}{c}{$\mathrm{C}$} \\
\hline 1 & D & $\mathrm{kg} / \mathrm{m}^{3}$ & 2209,24 & 2345,20 & 2216,08 \\
\hline 2 & Cement & $\mathrm{kg} / \mathrm{m}^{3}$ & 350,4 & 325,6 & 305,80 \\
\hline 3 & Water & $\mathrm{kg} / \mathrm{m}^{3}$ & 200,24 & 187,41 & 154,12 \\
\hline 4 & Agregat SSD & $\mathrm{kg} / \mathrm{m}^{3}$ & 1680,7 & 1864,89 & 1756,16 \\
\hline
\end{tabular}




\section{e. Gambar Struktur Mikro}

Pemeriksaan struktur mikro dilakukan terhadap contoh uji menggunakan Scaning electron microscopy (SEM). Gambar 1, memperlihatkan perbandingan kondisi struktur mikro pada tingkat perbesaran yang berbeda. Gambar 1, dengan kode sampel A dan perbesaran 5000x, memperlihatkan jejak volume C-S-H yang lebih banyak bila dibandingkan dengan Gambar 1 dengan kode sampel B dan perbesaran 5000x. Gambar 1, dengan kode B juga memiliki volume $\mathrm{C}-\mathrm{S}-\mathrm{H}$ lebih besar bila dibandingkan dengan Gambar 1, dengan kode sampel $\mathrm{C}$ dan perbesaran 5000x. Berdasarkan gambar-gambar tersebut memperlihatkan apabila semen yang digunakan lebih banyak akan menghasilkan C-S-H yang lebih banyak pula.

Pada hasil pengujian kdar kimia $\mathrm{CaO}$ dan $\mathrm{SiO}_{2}$ untuk benda uji $\mathrm{A}, \mathrm{B}$ dan $\mathrm{C}$, memperlihatkan benda uji A mempunyai kadar $\mathrm{CaO}$ dan $\mathrm{SiO}_{2}$ yang lebih besar bila dibandingkan dengan sampel B. Demikian juga sampel $\mathrm{B}$ juga memiliki kadar $\mathrm{CaO}$ dan $\mathrm{SiO}_{2}$ yang lebih besar bila dibandingkan dengan sampel $\mathrm{C}$. Pemeriksaan ini di tujukan untuk menghitung jumlah semen yang terkandung pada setiap adukan. Dengan mengetahui jumlah semen dalam setiap adukan maka dapat ditentukan besarnya jumlah air yang dipakai pada setiap adukan, seperti di sajikan pada Tabel 10. pengetahuan jumlah semen dan jumlah air dipergunakan untuk menghitung kadar agregat pada setiap adukan.

Kondisi struktur mikro dan kadar kimia yang terkandung dalam setiap benda uji mencerminkan kekuatan beton, dimana struktur mikro yang padat akan memberikan kuat tekan lebih baik, dibandingkan dengan struktur mikro yang kurang padat dan komposisi campuran beton.
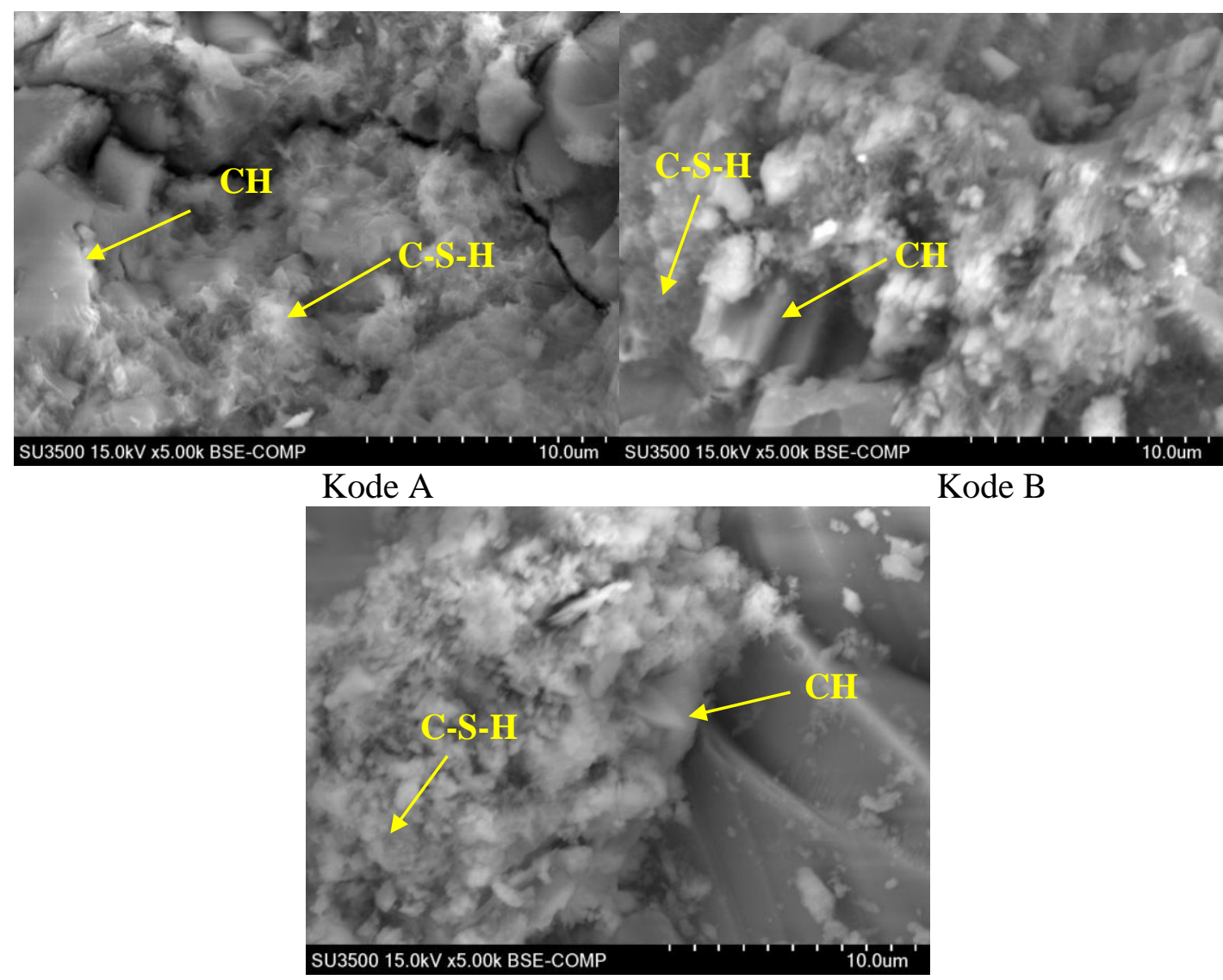

Kode C Kode B

Gambar 1. Foto SEM kode A, B, dan C perbesaran 5000 x 


\section{KESIMPULAN DAN SARAN}

\section{Kesimpulan}

Berdasarkan perhitungan yang dilakukan, teknik yang digunakan untuk menghitung nilai perbandingan jumlah air terhadap jumlah semen pada beton keras diperoleh hasil yang tidak jauh berbeda dengan rencana campuran yang dibuat. Kesimpulan hasil perhitungan tersebut seperti yang disajikan pada Tabel 11, berikut:

Tabel 11. Perkiraan komposisi material dan kekuatan beton

\begin{tabular}{|c|c|c|c|c|c|c|c|}
\hline \multirow{2}{*}{ No } & \multirow{2}{*}{ Kode } & \multirow{2}{*}{$\begin{array}{c}\text { DSSD } \\
\mathrm{kg} / \mathrm{m} 3\end{array}$} & \multicolumn{3}{|c|}{ Komposisi Material $\left(\mathrm{kg} / \mathrm{m}^{3}\right)$} & \multirow{2}{*}{$\begin{array}{l}\text { Perbandingan } \\
\text { Air/semen } \\
(\%)\end{array}$} & \multirow{2}{*}{$\begin{array}{c}\text { Perbandingan } \\
\text { Air/semen } \\
\text { Rencana } \\
(\%)\end{array}$} \\
\hline & & & Semen & Air & Agregat & & \\
\hline 1 & $\mathrm{~A}$ & $2.209,24$ & 370,47 & 200,24 & 1680,70 & 54,05 & 50,0 \\
\hline 2 & B & $2.345,20$ & 320,91 & 187,41 & 1864,89 & 58,40 & 50,0 \\
\hline 3 & $\mathrm{C}$ & $2.216,08$ & 301,86 & 154,12 & 1756,16 & 51,06 & 50,0 \\
\hline
\end{tabular}

Pengamatan yang dilakukan pada struktur mikro menggunakan SEM, jumlah air yang berlebihan menimbulkan banyak jejak berupa pori-pori, jumlah air yang berlebihan juga dapat menimbulkan keretakan sehingga beton menjadi tidak solid.

\section{Saran}

Pada pemeriksaan beton yang sudah mengeras, perlu dilakukan pengujian menggunakan alat intrusi porositymetri, untuk pengukuran yang lebuh akurat terhadap volume pori-pori beton. Ini penting dilakukan untuk menghitung jumlah air bebas yang terdeteksi melalui pori-pori kapiler.

\section{Ucapan Terima Kasih (Acknowledgement)}

Penulisan berkaitan dengan komposisi beton terus dilakukan untuk dapat menelusuri jejak komposisi beton yang digunakan dalam adukan. Disain campuran merupakan bagian yang paling penting dalam penyusunan material beton. Kadar air pada beton, kadar $\mathrm{CaO}$ dan $\mathrm{SiO}_{2}$ dalam semen dan kadar agregat kasar, merupakan jumlah yang tidak mudah untuk ditelusuri. Penulisan ini memberikan bagaimana menghitung ulang komposisi material pada beton yang sudah mengeras. Masih banyak sekali bagian yang harus diteliti terkait teknik yang digunakan untuk menguraikan, namun secara garis besar penulisan ini akan mampu menunjukkan bagaimana komposisi material beton dapat diuraikan melalui teknik yang disajikan dalam penulisan ini . Penulis mengucapkan terimakasih kepada semua pihak yang akan membantu pelaksanaan penelitian, terutama Lembaga Penelitian dan Pengabdian kepada Masyarakat (LPPM) Universitas Tarumanagara yang akan mendanai penelitian ini juga kepada para mahasiswa yang membantu Prem Singh, Charles dan Kevin Sidharta.

\section{REFERENSI}

Mindess, A. and Young, J. F. (1981). "Concrete”, Prentice-Hall, New Jersey.

Neville, A. (2003). "How closely we determine the wate-cement ratio of hardened concrete", Material and Structure, Vol 26, pp. 311-318.

Neville, A.M. (2011). "Properties of Concrete" $5^{\text {th }}$ Edittion, Pearson Education Limited. 
Rebelo, J. (2014). "Evaluation of Test Method for Determining the Water to Cement Ratio of Fresh and Hardened Concrete", A thesis Master of Applied Science Civil Engineering University of Toronto.

Tauqir, A. (2018). "Determination of water/cement-ratio of concrete", Master's thesis for the degree of Master of Science I Engineeering submitted for inspection. Aalto-University School of Engineering.

Wong, H. S. and Buenfeld, N. R. (2009). "Determining the water-cement ratio, cement content, water content and degree of hydration of hardened cement paste: Method development and validation on paste samples", Cement \& Concrete Research, vol. 29 no. 10, PP. 957-965. 
